Article

\title{
Incorporating the Vadose Zone into the Budyko Framework
}

\author{
Garrison Sposito ${ }^{1,2}$ \\ 1 Department of Environmental Science, Policy and Management, University of California, \\ Berkeley, CA 94720-3114, USA; gsposito@berkeley.edu; Tel.: +1-510-643-8297 \\ 2 Earth \& Environmental Sciences Area, Lawrence Berkeley National Laboratory, Berkeley, CA 94720, USA \\ Received: 27 June 2017; Accepted: 30 August 2017; Published: 13 September 2017
}

\begin{abstract}
The Budyko framework provides a quantitative description of long-term average annual evapotranspiration at catchment scales in terms of macro-climatic variables. This framework, however, makes no reference to the vadose zone because it neglects changes in subsurface storage in the catchment water balance. Recent studies have shown clearly that vadose-zone water storage cannot be neglected at sub-catchment or sub-annual space and time scales, resulting in numerous model attempts to extend the original Budyko framework to incorporate the full water balance equation. Here we apply the approach taken in a companion paper on the original Budyko framework to show that it can be generalized rigorously to include changes in vadose-zone water storage in a manner that is both parsimonious in hypotheses and broad in scope.
\end{abstract}

Keywords: Budyko equation; evapotranspiration; catchment hydrology; vadose zone; water balance

\section{Introduction}

The Budyko framework [1] is the name given to an implicit mathematical relationship between catchment evapotranspiration (ET) and two macro-climatic variables, precipitation (P) and potential evapotranspiration $\left(\mathrm{ET}_{0}\right)$, originally put forth by Budyko [2] (pp. 322-323). This relationship can be expressed as:

$$
\mathrm{ET}=\mathrm{f}\left(\mathrm{P}, \mathrm{ET}_{0}\right)
$$

Equation (1) is subject to the boundary conditions [2-4]:

$$
\begin{aligned}
& \mathrm{ET} \rightarrow \mathrm{ET}_{0} \text { as } \mathrm{P} \uparrow \infty \text { (energy supply is limiting) } \\
& \mathrm{ET} \rightarrow \mathrm{P} \text { as } \mathrm{ET}_{0} \uparrow \infty \text { (water supply is limiting) }
\end{aligned}
$$

As discussed by Budyko ([2] pp. 322-323), Equation (2) states that ET will take on its potential value in the limit of an infinitely abundant precipitation input, while Equation (3) indicates that ET will consume all precipitation in the limit of an infinitely abundant energy input.

The Budyko framework was developed under the assumption of steady-state water balance, which equates precipitation to the sum of evapotranspiration and runoff, thus implying negligible changes in subsurface water storage [2-4]. This assumption has been validated in observations of long-term average annual ET from large catchments, but it is known to fail at smaller temporal and spatial scales [3]. For example, the boundary condition in Equation (3) can be violated by annual ET from an arid sub-catchment if ET exceeds P because of contributions from water stored in the vadose zone $[5,6]$. Therefore, in order to describe ET under non-steady-state conditions, the assumption of negligible changes in subsurface water storage must be relaxed and Equation (1) must be accordingly generalized [1,3,5]:

$$
\mathrm{ET}=\mathrm{f}\left(\mathrm{P}, \mathrm{ET}_{0}, \Delta \mathrm{S}\right)
$$


where $\Delta S$ designates a change in subsurface water storage, either a gain or a loss.

In a recent comprehensive review of the Budyko framework, Wang et al. [3] have discussed numerous attempts to extend the Budyko framework based on Equation (4), noting their use of adjustable parameters with no a priori relationship to catchment properties and their tendency to conflate climatic variability with catchment variability. They concluded that additional research was needed to "advance the Budyko framework with respect to model parsimony and physical meaning" [3] (p. 17). The present paper is a response to this challenge. It will be shown that, by making a single physically-relevant hypothesis about the functional relationship in Equation (4), the Budkyo framework can be extended to include changes in vadose-zone water storage in a manner broad enough to include all extant models $[1,3,6]$ as special cases, while offering a rigorous approach to the specific modeling of Equation (4) that does not require adjustable parameters.

\section{Extending the Budyko Framework}

\subsection{The Homogeneity Postulate}

The Budyko framework can be extended to include changes in vadose-zone water storage as an independent variable in a manner consistent with the original framework [2,4] by postulating that $\mathrm{f}\left(\mathrm{P}, \mathrm{ET}_{0}, \Delta \mathrm{S}\right)$ in Equation (4) is a homogeneous function of its arguments; meaning that if the independent variables are each multiplied by an arbitrary scale factor, $\lambda$, the value of $f\left(P, \mathrm{ET}_{0}, \Delta \mathrm{S}\right)$ is multiplied by the same scale factor, $\lambda[4,7]$ :

$$
\mathrm{f}\left(\lambda \mathrm{P}, \lambda \mathrm{ET}_{0}, \lambda \Delta \mathrm{S}\right)=\lambda \mathrm{f}\left(\mathrm{P}, \mathrm{ET}_{0}, \Delta \mathrm{S}\right)
$$

Sposito [4] demonstrated in a companion to the present paper that the homogeneity hypothesis applied to the original Budyko framework, Equation (1), is sufficiently broad to include all extant models of long-term average annual catchment ET, parametric or non-parametric, as special cases. The same will be shown in the present paper for the extended Budkyko framework, Equation (4).

Following Hankey and Stanley [7], one can prove that the assumed property of homogeneity is both necessary and sufficient to express Equation (4) in two equivalent forms:

$$
\mathrm{ET}=\mathrm{PF}\left(\frac{\mathrm{ET}_{0}}{\mathrm{P}}, \frac{\Delta \mathrm{S}}{\mathrm{P}}\right)
$$

or

$$
\mathrm{ET}=\mathrm{ET}_{0} \mathrm{~F}\left(\frac{\mathrm{P}}{\mathrm{ET}_{0}}, \frac{\Delta \mathrm{S}}{\mathrm{ET}_{0}}\right)
$$

Equation (6) constitutes the "Budyko picture" of ET in the "Budyko space", i.e., ET/P as a function of $\mathrm{ET}_{0} / \mathrm{P}$ and $\Delta \mathrm{S} / \mathrm{P}$, while Equation (7) constitutes the "Turc picture" of ET in the "Turc space", i.e., $\mathrm{ET} / \mathrm{ET}_{0}$ as a function of $\mathrm{P} / \mathrm{ET}_{0}$ and $\Delta \mathrm{S} / \mathrm{ET}_{0}[1,8]$. In the present paper, only the Budyko picture will be utilized. For a detailed comparison of the Budyko and Turc pictures, see $[1,8]$.

Equation (6) implies that, with respect to ET, two terrestrial regions at different geographic locations, or the same region at two different time periods, are scaled versions of one another. Thus, any two regions, or the same region at different times, exhibiting the same values of $\mathrm{ET}_{0} / \mathrm{P}$ and $\Delta \mathrm{S} / \mathrm{P}$ are in corresponding ET states. This "law of corresponding states" [4], an example of hydrologic similarity/space-time symmetry [9], is demonstrated experimentally by the close clustering of ET data when plotted according to Equation (6). Such a test was first performed systematically by Budyko [2] (pp. 325-327) in the original framework (i.e., neglecting $\Delta S / P$ ) using long-term hydrologic and climatological data for more than 1000 catchments and thereafter has been tested in a large number of careful studies [10-14]. The study of Ye et al. [13], which confirms the law of corresponding states in the original framework with data collected daily over half a century in more than 250 catchments located in a variety of climatic zones and physiographic regions, is exemplary. 


\subsection{Boundary Conditions}

In the original Budyko framework, the well-known boundary conditions on ET/P corresponding to Equations (2) and (3) are [2-4,15]:

$$
\begin{aligned}
& \frac{\mathrm{ET}}{\mathrm{P}} \downarrow 0 \text { as } \frac{\mathrm{ET}_{0}}{\mathrm{P}} \downarrow 0 \text { (energy-supply limit) } \\
& \frac{\mathrm{ET}}{\mathrm{P}} \uparrow 1 \text { as } \frac{\mathrm{ET}_{0}}{\mathrm{P}} \uparrow \infty \text { (water-supply limit) }
\end{aligned}
$$

However, if $\Delta S \neq 0$, Equations (8) and (9) are not in general applicable because stored vadose-zone water can serve either as an additional source of ET or as a sink for P. If $\Delta S<0$, the minimum value of ET/P in the energy-supply limit is not 0, as in Equation (8), because there are now two sources of ET, precipitation and stored vadose-zone water, so the minimum value of ET/P in the energy-supply limit would correspond to ET derived wholly from stored vadose-zone water [1,16], while P is transformed solely into runoff, in which case $\mathrm{ET}=-\Delta \mathrm{S}$. Since by definition $\mathrm{ET}=\mathrm{ET}_{0}$ in the energy-supply limit, Equation (8) becomes [1]:

$$
\frac{\mathrm{ET}}{\mathrm{P}} \downarrow-\frac{\Delta \mathrm{S}}{\mathrm{P}} \text { as } \frac{\mathrm{ET}_{0}}{\mathrm{P}} \downarrow-\frac{\Delta S}{\mathrm{P}},(\Delta S<0)
$$

On the other hand, if $\Delta S>0$, the minimum value of $E T / P$ remains at 0 , which corresponds to $P$ transformed either into runoff or water stored in the vadose zone $[1,17]$. Therefore, Equation (8) remains valid.

In the water-supply limit, the maximum value of ET/P is not equal to 1, as in Equation (9), but instead equals $[1-(\Delta S / P)]$, which corresponds to stored water serving either as an additional source of ET $(\Delta S<0)$, thus increasing it, or as a sink for P that reduces ET $(\Delta S>0)$ [1]. Therefore, Equation (9) becomes [1]:

$$
\frac{\mathrm{ET}}{\mathrm{P}} \uparrow[1-(\Delta \mathrm{S} / \mathrm{P})] \text { as } \frac{\mathrm{ET}_{0}}{\mathrm{P}} \uparrow \infty
$$

Graphical examples of Equations (10) and (11) are presented in [1,5,16].

\subsection{The Euler Relation}

In addition to the scaling relationship in Equation (5), all homogeneous functions satisfy the Euler relation, as discussed in detail for the original Budyko framework in [4]. The Euler relation following from the assumption of homogeneity for $\mathrm{f}\left(\mathrm{P}, \mathrm{ET}_{0}, \Delta \mathrm{S}\right)$ is:

$$
\mathrm{ET}=\left(\frac{\partial \mathrm{ET}}{\partial \mathrm{P}}\right)_{\mathrm{ET}_{0}, \Delta \mathrm{S} P}+\left(\frac{\partial \mathrm{ET}}{\partial \mathrm{ET}_{0}}\right)_{\mathrm{P}, \Delta \mathrm{S}} \mathrm{ET}_{0}+\left(\frac{\partial \mathrm{ET}}{\partial \Delta \mathrm{S}}\right)_{{\mathrm{P}, \mathrm{ET}_{0}}_{0}} \Delta \mathrm{S}
$$

which is derived from Equation (5) by differentiating both sides with respect to $\lambda$ then setting $\lambda=1$ and noting Equation (4). As in the original Budyko framework [4,18], the partial derivatives in Equation (12) are subject to boundary conditions following from those in Equations (10) and (11):

$$
\begin{gathered}
\left(\frac{\partial \mathrm{ET}}{\partial \mathrm{P}}\right)_{\mathrm{ET}_{0}, \Delta \mathrm{S}} \downarrow \\
0 \text { as } \frac{\mathrm{ET}_{0}}{\mathrm{P}} \downarrow-\frac{\Delta \mathrm{S}}{\mathrm{P}}(\Delta \mathrm{S}<0) \text { or } 0(\Delta \mathrm{S}>0) \\
\left(\frac{\partial \mathrm{ET}}{\partial \mathrm{P}}\right)_{\mathrm{ET}_{0}, \Delta \mathrm{S}} \uparrow 1 \text { as } \frac{\mathrm{ET}_{0}}{\mathrm{P}} \uparrow \infty \\
\left(\frac{\partial \mathrm{ET}}{\partial \mathrm{ET}_{0}}\right)_{\mathrm{P}, \Delta \mathrm{S}} \uparrow 1 \text { as } \frac{\mathrm{ET}_{0}}{\mathrm{P}} \downarrow-\frac{\Delta \mathrm{S}}{\mathrm{P}}(\Delta \mathrm{S}<0) \text { or } 0(\Delta \mathrm{S}>0) \\
\left(\frac{\partial \mathrm{ET}}{\partial \mathrm{ET}}\right)_{\mathrm{P}, \Delta \mathrm{S}} \downarrow 0 \text { as } \frac{\mathrm{ET}_{0} \uparrow \infty}{\mathrm{P}} \uparrow \infty
\end{gathered}
$$




$$
\begin{gathered}
\left(\frac{\partial \mathrm{ET}}{\partial \Delta \mathrm{S}}\right)_{\mathrm{P}, \mathrm{ET}_{0}} \downarrow \\
\left(\frac{\partial \mathrm{ET}}{\partial \Delta \mathrm{S}}\right)_{\mathrm{P}, \mathrm{ET}_{0}} \uparrow-1 \text { as } \frac{\mathrm{ET}_{0}}{\mathrm{P}} \uparrow \infty
\end{gathered}
$$

The substitution of the six boundary conditions in Equations (13)-(18) into Equation (12) reproduces the boundary conditions in Equations (10) and (11). Graphs illustrating the boundary conditions in Equations (13)-(16) in the original Budyko framework are given in Figure 6 of [18] based on a parametric model of Equation (6) for the case $\Delta S=0$. See also Figure 6 in [14] and Figure 3 in [11] for illustrative plots of $(\partial \mathrm{ET} / \partial \mathrm{P})$ versus $\mathrm{ET}_{0} / \mathrm{P}$ in the original Budyko framework.

The physical interpretation of these boundary conditions is as follows (see also [19]). Equations (13) and (15) reflect the fact that, when the water supply is not limiting, ET becomes insensitive to changes in $\mathrm{P}$ and approaches its maximum value, $\mathrm{ET}_{0}$. Equations (14) and (16) reflect the opposite tendency, i.e., the water supply is limiting and all available $\mathrm{P}$ is consumed by ET, which then becomes insensitive to changes in $\mathrm{ET}_{0}$. Equations (17) and (18) are unique to the extended Budyko framework. They are, however, analogous to Equations (13) and (14): ET becomes insensitive to changes in $\Delta S$ when the water supply is not limiting, akin to its insensitivity to $\mathrm{P}$, whereas when the water supply is limiting, ET becomes very sensitive to changes in $\Delta S$ for the same reason that it is very sensitive to changes in $P$. Thus Equations (13) and (17) and Equations (14) and (18) express complementary water-balance effects on ET. The difference in sign between the right sides of Equations (14) and (18) is because ET increases as $\mathrm{P}$ increases, whereas ET decreases as $\Delta \mathrm{S}$ increases.

Lastly, as shown in detail in [4], only two of the partial derivatives in the Euler relation, Equation (12), can be specified independently because of the constraint imposed by the Gibbs-Duhem equation, which follows from calculating the total differential of ET using the Euler relation then comparing the result with the total differential of ET based on Equation (4). The two independent partial derivatives are conveniently chosen to be the climate elasticities, $\left(\frac{\partial \mathrm{ET}}{\partial \mathrm{P}}\right)_{\mathrm{ET}_{0}, \Delta \mathrm{S}}$ and $\left(\frac{\partial \mathrm{ET}}{\partial \mathrm{ET}_{0}}\right)_{\mathrm{P}, \Delta \mathrm{S}^{\prime}}$ which have often been modeled to investigate the effects of climate variability on ET $[3,4,14]$.

\section{Special Case: The Moussa-Lhomme Formulation}

\subsection{Basic Postulates}

Moussa and Lhomme [1] have recently formulated an extended Budyko framework which is a special case of the general framework presented here. The underlying physical motivation for their formulation lies in the observations that (1) while the original Budyko framework postulates the entirety of ET as derived from $\mathrm{P}$, in the extended Budyko framework it is only the portion $(\mathrm{ET}+\Delta \mathrm{S})$ that is derived from $P$ if $\Delta S<0$ and (2) while the entirety of $P$ is available for ET in the original Budyko framework, only the portion $(\mathrm{P}-\Delta \mathrm{S})$ is available for ET in the extended Budyko framework if $\Delta \mathrm{S}>0$. This line of reasoning, based solely on the complete water balance, can be summarized in the following two hypotheses:

(1) For $\Delta S<0$, the portion of ET that is derived from precipitation, $(E T+\Delta S)$, has the same functional relationship to $\left(\mathrm{ET}_{0}+\Delta \mathrm{S}\right)$ in the extended Budyko framework as $\mathrm{ET}$ does to $\mathrm{ET}_{0}$ in the original Budyko framework, i.e., if

$$
\frac{\mathrm{ET}}{\mathrm{P}}=\mathrm{B}\left(\frac{\mathrm{ET}_{0}}{\mathrm{P}}\right)
$$

in the original Budyko framework, then

$$
\frac{\mathrm{ET}+\Delta \mathrm{S}}{\mathrm{P}}=\mathrm{B}\left(\frac{\mathrm{ET}_{0}+\Delta \mathrm{S}}{\mathrm{P}}\right)
$$


in the extended framework, where $\mathrm{B}\left(\frac{\mathrm{ET}_{0}+\Delta \mathrm{S}}{\mathrm{P}}\right)$ has the same mathematical form as the model function, $\mathrm{B}\left(\mathrm{ET}_{0} / \mathrm{P}\right)$, found suitable for representing $\mathrm{ET} / \mathrm{P}$ in the original framework, but with $\mathrm{ET}_{0} / \mathrm{P}$ in $\mathrm{B}\left(\mathrm{ET}_{0} / \mathrm{P}\right)$ replaced by $\left(\mathrm{ET}_{0}+\Delta \mathrm{S}\right) / \mathrm{P}$ in $\mathrm{B}\left(\frac{\mathrm{ET}_{0}+\Delta \mathrm{S}}{\mathrm{P}}\right)$.

(2) For $\Delta \mathrm{S}>0, \mathrm{ET} /(\mathrm{P}-\Delta \mathrm{S})$, where $(\mathrm{P}-\Delta \mathrm{S})$ is the portion of $\mathrm{P}$ that is available for transformation into $\mathrm{ET}$, has the same functional relationship to $\mathrm{ET}_{0} /(\mathrm{P}-\Delta \mathrm{S})$ as $\mathrm{ET} / \mathrm{P}$ does to $\mathrm{ET}_{0} / \mathrm{P}$ in the original Budyko framework, i.e.,

$$
\frac{\mathrm{ET}}{\mathrm{P}-\Delta \mathrm{S}}=\mathrm{B}\left(\frac{\mathrm{ET}_{0}}{\mathrm{P}-\Delta \mathrm{S}}\right)
$$

where $\mathrm{B}\left(\frac{\mathrm{ET}_{0}}{\mathrm{P}-\Delta \mathrm{S}}\right)$ has the same mathematical form as $\mathrm{B}\left(\mathrm{ET}_{0} / \mathrm{P}\right)$ in the original Budyko framework but with $\mathrm{ET}_{0} / \mathrm{P}$ in $\mathrm{B}\left(\mathrm{ET}_{0} / \mathrm{P}\right)$ replaced by $\mathrm{ET}_{0} /(\mathrm{P}-\Delta \mathrm{S})$ in $\mathrm{B}\left(\frac{\mathrm{ET}_{0}}{\mathrm{P}-\Delta \mathrm{S}}\right)$.

Under these two hypotheses, any model of $\mathrm{ET} / \mathrm{P}=\mathrm{B}\left(\mathrm{ET}_{0} / \mathrm{P}\right)$ found suitable for application in the original Budyko framework to represent ET/P is automatically a candidate for use in the Moussa-Lhomme (ML) extended Budyko framework. Moussa and Lhomme [1] have tabulated several such candidate functions from the literature based on both parametric and non-parametric models of $\mathrm{ET} / \mathrm{P}$.

The Euler relation, Equation (12), takes on a simplified form in the ML extended Budyko framework because of the two hypotheses above, noting that, given the constraint in Equation (19), $\left(\frac{\partial \mathrm{ET}}{\partial \Delta \mathrm{S}}\right)_{\mathrm{P}, \mathrm{ET}_{0}}$ can always be expressed as a function of the climate elasticities. It is straightforward to demonstrate by the direct incorporation of Hypotheses (1) and (2) into Equation (12) with the third term neglected that, in the ML formulation, the Euler relation becomes:

$$
\mathrm{ET}=-\Delta \mathrm{S}+\left(\frac{\partial \mathrm{ET}}{\partial \mathrm{P}}\right)_{\mathrm{ET}_{0}, \Delta \mathrm{S}} \mathrm{P}+\left(\frac{\partial \mathrm{ET}}{\partial \mathrm{ET}_{0}}\right)_{\mathrm{P}, \Delta \mathrm{S}}\left(\mathrm{ET}_{0}+\Delta \mathrm{S}\right)
$$

and

$$
\mathrm{ET}=\left(\frac{\partial \mathrm{ET}}{\partial \mathrm{P}}\right)_{\mathrm{ET}_{0}, \Delta \mathrm{S}}(\mathrm{P}-\Delta S)+\left(\frac{\partial \mathrm{ET}}{\partial \mathrm{ET}_{0}}\right)_{\mathrm{P}, \Delta \mathrm{S}} \mathrm{ET}_{0},(\Delta \mathrm{S}>0)
$$

\subsection{Example: Extending the Schreiber Model}

The ML formulation can be illustrated in perhaps the simplest manner with the Schreiber model, cited by Budyko [2] (p. 323) as the earliest published mathematical expression of the relationship $\mathrm{ET} / \mathrm{P}=\mathrm{B}\left(\mathrm{ET}_{0} / \mathrm{P}\right)$. The Schreiber model is non-parametric, conforming to the boundary conditions in Equations (8) and (9) while interpolating smoothly between them. It is often used as a basis for comparison with parametric models [15].

As noted above, if models of the climate elasticities are available, they can be substituted into the Euler relation to derive an expression for ET/P. In the Schreiber model, the climate elasticities are:

$$
\begin{gathered}
\left(\frac{\partial \mathrm{ET}}{\partial \mathrm{P}}\right)_{\mathrm{ET}_{0}}=1-(1+\varphi) \exp (-\varphi) \\
\left(\frac{\partial \mathrm{ET}}{\partial \mathrm{ET}_{0}}\right)_{\mathrm{P}}=\exp (-\varphi)
\end{gathered}
$$

where $\varphi=\mathrm{ET}_{0} / \mathrm{P}$ is the well-known aridity index [3,11]. The partial derivatives in Equations (24) and (25) conform to the boundary conditions in Equations (13)-(16), with $\Delta S=0$. The physical basis for Equation (24) is that, for a given $\mathrm{ET}_{0}$, the sensitivity of ET to $\mathrm{P}$ increases with $\mathrm{ET}_{0}$, a measure of the energy that can be potentially transported to the atmosphere if $\mathrm{P}$ is not limiting, whereas it decreases with increasing P as the water supply for ET becomes more plentiful. The physical basis for Equation (25) is that, for a given $\mathrm{P}$, the sensitivity of $\mathrm{ET}$ to $\mathrm{ET}_{0}$ increases with $\mathrm{P}$, the amount of water 
that potentially can be transported to the atmosphere if $\mathrm{ET}_{0}$ is not limiting, whereas it decreases with increasing $\mathrm{ET}_{0}$ as the energy supply for ET becomes more plentiful.

Upon the substitution of Equations (24) and (25) into the Euler relation, Equation (12) with $\Delta S=0$, the Schreiber model is derived in the original Budyko framework [2] (p. 323):

$$
\mathrm{ET} / \mathrm{P}=\mathrm{B}(\varphi)=1-\exp (-\varphi)
$$

Equation (26) is readily seen to conform to the boundary conditions in Equations (8) and (9). According to the ML formulation, the Schreiber model, when extended to include $\Delta S$, should become:

$$
\mathrm{ET} / \mathrm{P}=\mathrm{B}\left(\varphi^{\prime}\right)=-\Delta \mathrm{S} / \mathrm{P}+1-\exp \left(-\varphi^{\prime}\right)
$$

for $\Delta \mathrm{S}<0$, where $\varphi^{\prime}=\varphi+\Delta \mathrm{S} / \mathrm{P}$ is a modified aridity index. For $\Delta \mathrm{S}>0$, the extended Schreiber model becomes:

$$
\mathrm{ET} / \mathrm{P}=\mathrm{B}\left(\varphi^{*}\right)=[1-(\Delta \mathrm{S} / \mathrm{P})]\left[1-\exp \left(-\varphi^{*}\right)\right]
$$

where $\varphi^{*}=\varphi /(1-\Delta S / P)$ is another modified aridity index. Equation (27) conforms to the boundary conditions in Equations (10) and (11), while Equation (28) conforms to those in Equations (8) and (11). Both model equations reduce to Equation (26) when $\Delta S=0$.

Sankarasubramanian and Vogel $[20,21]$ have shown that a model incorporating subsurface water storage and having the same mathematical form as Equation (28) provides a quantitative description of ET/P calculated using databases on climate and runoff for more than 1000 catchments in the United States. Their model expression has the form:

$$
\mathrm{F}(\varphi, \gamma)=\gamma[1-\exp (-\varphi / \gamma)]
$$

where $\gamma=\mathrm{b} / \mathrm{P}$ and the parameter $\mathrm{b}>0$ represents the water-holding capacity of the upper vadose zone as defined in the abcd model of monthly catchment water balance [20-22]. If Equations (28) and (29) were physically equivalent, then the identification $\gamma=[1-(\Delta \mathrm{S} / \mathrm{P})]=(\mathrm{P}-\Delta \mathrm{S}) / \mathrm{P}$, with $\Delta \mathrm{S}>0$, could be made. Although this identification is consistent with the fact that $\gamma<1$ is overwhelmingly observed among catchments in the United States [22], the abcd model parameter b represents a water-holding capacity in soil [20-22] that cannot be equated with $(\mathrm{P}-\Delta \mathrm{S})$, the portion of precipitation that has not been used to increase vadose-zone water storage and, therefore, is available for ET and runoff. This example illustrates how goodness-of-fit to ET/P data is not sufficient to discriminate among proposed evapotranspiration models that differ in their underlying hydrologic basis. The only valid way to do a comparison is to test the physical assumptions underlying the models, which, in the present case, is a comparison of the abcd model as applied in [20,21] with ML hypothesis (2) above, which led to Equation (28).

\section{Discussion}

The two principal elements of the extended Budyko framework under the assumption of homogeneity are: Equation (6), the extended Budyko equation, which relates ET/P to the scaled variables, $\mathrm{ET}_{0} / \mathrm{P}$ and $\Delta \mathrm{S} / \mathrm{P}$ and thus implies hydrologic similarity/space-time symmetry [9], and Equation (12), the Euler relation, which implies that the calculation of ET/P requires only a knowledge of the two climate elasticities, $\left(\frac{\partial \mathrm{ET}}{\partial \mathrm{P}}\right)_{\mathrm{ET}_{0}, \Delta \mathrm{S}}$ and $\left(\frac{\partial \mathrm{ET}}{\partial \mathrm{ET}_{0}}\right)_{\mathrm{P}, \Delta \mathrm{S}}$, because the constraint imposed by the Gibbs-Duhem equation [4] makes modeling the third partial derivative in Equation (12), $\left(\frac{\partial \mathrm{ET}}{\partial \Delta \mathrm{S}}\right)_{\mathrm{P}, \mathrm{ET}_{0}}$, redundant. Equations (22) and (23) give examples of this simplification.

The ML formulation of the extended Budyko framework is a special case of the general approach described in the present paper. It follows from two physical hypotheses: 
(1) For $\Delta S<0$, $(E T+\Delta S)$ plays the same role in water balance in the extended framework as ET does in the original framework, and, therefore, $(\mathrm{ET}+\Delta \mathrm{S}) / \mathrm{P}$ can be modeled by any function found suitable for modeling $\mathrm{ET} / \mathrm{P}$ in the original framework, with $\left(\mathrm{ET}_{0}+\Delta \mathrm{S}\right) / \mathrm{P}$ replacing $\mathrm{ET}_{0} / \mathrm{P}$ as the independent variable.

(2) For $\Delta S>0,(P-\Delta S)$ plays the same role in water balance in the extended framework as $P$ does in the original framework, and, therefore, ET $/(\mathrm{P}-\Delta \mathrm{S})$ can be modeled by any function found suitable for representing $\mathrm{ET} / \mathrm{P}$ in the original framework, with $\mathrm{ET}_{0} /(\mathrm{P}-\Delta \mathrm{S})$ replacing $\mathrm{ET}_{0} / \mathrm{P}$ as the independent variable.

The Schreiber model of ET/P [2] was used in Section 3.2 to demonstrate the application of these hypotheses, but more realistic models developed in the original Budyko framework can be transformed in the same way, as shown in [1]. For example, according to the ML hypothesis (1), the Fu model [19], which has been widely applied in the original Budyko framework [3,4],

$$
\frac{\mathrm{ET}}{\mathrm{P}}=1+\frac{\mathrm{ET}_{0}}{\mathrm{P}}-\left[1+\left(\frac{\mathrm{ET}_{0}}{\mathrm{P}}\right)^{\mathrm{w}}\right]^{1 / \mathrm{w}},(\mathrm{w}>1)
$$

in the ML formulation becomes, for the case $\Delta S<0$ :

$$
\frac{\mathrm{ET}+\Delta \mathrm{S}}{\mathrm{P}}=1+\frac{\mathrm{ET}_{0}+\Delta \mathrm{S}}{\mathrm{P}}-\left[1+\left(\frac{\mathrm{ET}_{0}+\Delta \mathrm{S}}{\mathrm{P}}\right)^{\mathrm{w}}\right]^{1 / \mathrm{w}},(\mathrm{w}>1)
$$

Equation (31) is discussed further in the Appendix A in relation to recent efforts to extend the Fu model by Moussa and Lhomme [1] and Greve et al. [6].

As noted above, the ML formulation can be applied to generalize any model function, $\mathrm{B}\left(\mathrm{ET}_{0} / \mathrm{P}\right)$, found suitable for use in the original Budyko framework, independently of whether the model contains an adjustable parameter such as w [1]. In light of this parameter independence, recent studies carried out in the original Budyko framework [3,15,23-25], which present statistical correlations between the Fu model parameter $\mathrm{w}$ and non-climatic catchment characteristics, may be premature, pending investigation of which catchment characteristics are already incorporated implicitly by considering the complete catchment water balance and including the independent variable, $\Delta \mathrm{S}$. Equation (28) offers a case in point, since varying $\Delta \mathrm{S} / \mathrm{P}$ in this equation has the same shape-changing effect on the $\mathrm{ET} / \mathrm{P}$ versus $\mathrm{ET}_{0} / \mathrm{P}$ curve as does varying $\mathrm{w}$ in Equation (30), which neglects vadose-zone water storage.

It must be noted in passing that the ML formulation has not been tested extensively against experimental data, although, as Moussa and Lhomme [1] have pointed out, the behavior of model equations in their formulation as functions of $\mathrm{ET}_{0} / \mathrm{P}$ is consistent with experimental data on catchment ET/P reported by others whose successful models of these data are special cases of the ML formulation $[5,6,16,26]$. The ML formulation is also consistent with the compilation of ET/P data for catchments in the United States reported by Sankarasubramanian and Vogel [20,21], as discussed above. Thus, further testing of the ML formulation with large data sets, particularly those that have been used in establishing statistical correlations between a model parameter such as $\mathrm{w}$ and catchment characteristics, is warranted and likely to be fruitful.

Acknowledgments: This paper and its companion, "Understanding the Budyko Equation", are dedicated to the memory of Bo Bodvarsson, under whose leadership, characterized by keen imagination and good humor, the author was privileged to work at Berkeley Lab. The research reported was supported in part by funds allocated in connection with the author's appointment as Chancellor's Professor, Emeritus, in the University of California at Berkeley.

Conflicts of Interest: The author declares no conflict of interest. The funding sponsor had no role in the design of the study; in the collection, analyses, or interpretation of data; in the writing of the manuscript; or in the decision to publish the results. 


\section{Appendix A. Extending the Fu Model}

Greve et al. [6] developed a model expression for ET/P in an extended Budyko framework by "including a new parameter explicitly representing additional water available to evapotranspiration besides instantaneous precipitation" [6] (p. 2195). This new parameter, $y_{0}$, was incorporated by Greve et al. [6] into the Fu model in the original Budyko framework [19] in order to generalize it for application in an extended Budyko framework.

The Fu model is based on two physical assumptions about the dependence of the climate elasticities on ET, $\mathrm{P}$, and $\mathrm{ET}_{0}$ [19]:

(1) For a given value of $\mathrm{ET}_{0},(\partial \mathrm{ET} / \partial \mathrm{P})$ increases with $\left(\mathrm{ET}_{0}-\mathrm{ET}\right)$, a measure of the energy that could have been transported to the atmosphere by ET if $\mathrm{P}$ were not limiting, while it decreases with increasing $P$.

(2) For a given value of $\mathrm{P},\left(\partial \mathrm{ET} / \partial \mathrm{ET}_{0}\right)$ increases with $(\mathrm{P}-\mathrm{ET})$, the volume of water that could have been transported to the atmosphere by $\mathrm{ET}$ if $\mathrm{ET}_{0}$ were not limiting, while it decreases with increasing $\mathrm{ET}_{0}$.

These assumptions modify those underlying the Schreiber model by referencing $\mathrm{ET}_{0}$ and $\mathrm{P}$ to ET in the factors that cause the climate elasticities to increase. The expressions for the Fu model climate elasticities as modified by Greve et al. [6] through the introduction of their new parameter, $\mathrm{y}_{0}$, are:

$$
\begin{gathered}
\left(\frac{\partial \mathrm{ET}}{\partial \mathrm{P}}\right)_{\mathrm{ET}_{0}, \mathrm{y}_{0}}=1-\left[1+\frac{\left(\mathrm{ET}_{0}-\mathrm{ET}\right)}{\mathrm{P}}\right]^{1-w} \\
\left(\frac{\partial \mathrm{ET}}{\partial \mathrm{ET}_{0}}\right)_{\mathrm{P}, \mathrm{y}_{0}}=1-\left(1-\mathrm{y}_{0}\right)^{\mathrm{w}-1}\left(1+\frac{(\mathrm{P}-\mathrm{ET})}{\mathrm{ET}_{0}}\right)^{1-\mathrm{w}}
\end{gathered}
$$

If $\mathrm{y}_{0}=0$, the original Fu model climate elasticities are recovered $[4,19]$.

Greve et al. [6] interpreted $\mathrm{y}_{0}$ as the maximum value of (ET - P)/ET $\mathrm{ET}_{0}$ corresponding to "the maximum amount of additional water that contributes to ET and originates from other sources than $\mathrm{P}^{\prime \prime}[6]$ (p. 2199). Thus $\mathrm{y}_{0}>0$, with its numerator representing the contribution to ET from a change in vadose-zone water storage, i.e., the numerator in $\mathrm{y}_{0}$ is $-\Delta \mathrm{S}$ and $\mathrm{y}_{0}=-\Delta \mathrm{S} / \mathrm{ET}_{0}$. In deriving an equation for ET/P from Equations (A1) and (A2), Greve et al. [6] followed the method in [19] to integrate them as partial differential equations. However, they assumed that $\mathrm{y}_{0}$ was constant in their integration of $\left(\partial \mathrm{ET} / \partial \mathrm{ET}_{0}\right)$, a point which can be seen explicitly in their Equation (A13), showing $\mathrm{y}_{0}$ taken outside the integral over $\mathrm{ET}_{0}$. This assumption, however, implies that $\Delta \mathrm{S}$ is proportional to $\mathrm{ET}_{0}$, which is not consistent with $\Delta \mathrm{S}$ being an independent variable, aside from the fact that no physical basis for $\Delta \mathrm{S}$ being proportional to $\mathrm{ET}_{0}$ is apparent. The integral over $\mathrm{ET}_{0}$ performed by Greve et al. [6] should have included the term in $\mathrm{y}_{0}$ under the integral sign, with $\mathrm{y}_{0}$ set equal to $-\Delta \mathrm{S} / \mathrm{ET}_{0}$ and $\Delta \mathrm{S}$, not $\mathrm{y}_{0}$, and held constant. If the integration is performed in this way, the resulting extended Fu model expression for $\mathrm{ET} / \mathrm{P}$ is:

$$
\frac{\mathrm{ET}}{\mathrm{P}}=1+\phi-\left[1+\left(1-\mathrm{y}_{0}\right)^{\mathrm{w}} \phi^{\mathrm{w}}\right]^{1 / \mathrm{w}}
$$

where $\varphi$ has the same meaning as in Equation (26). If $\mathrm{y}_{0}=0$, Equation (A3) reduces to the Fu model for ET/P [4,19]. Moreover, since $\mathrm{y}_{0}>0$, the right side of Equation (A3) approaches $\left(1+\mathrm{y}_{0} \varphi\right)$ as $\varphi \uparrow \infty$, i.e., ET/P approaches $[1-(\Delta \mathrm{S} / \mathrm{P})]$, in agreement with Equation (11).

Instead of following the parametric approach of Greve et al. [6], one can generalize the climate elasticities in the Fu model (Equations (A1) and (A2), with $\mathrm{y}_{0}=0$ ) for the case $\Delta \mathrm{S}<0$ by invoking the first hypothesis in the ML formulation, with the result:

$$
\left(\frac{\partial \mathrm{ET}}{\partial \mathrm{P}}\right)_{\mathrm{ET}_{0}, \Delta \mathrm{S}}=1-\left(1+\left(\phi+\frac{\Delta \mathrm{S}}{\mathrm{P}}\right)-\frac{(\mathrm{ET}+\Delta \mathrm{S})}{\mathrm{P}}\right)^{1-\mathrm{w}}=\left(1+\phi-\frac{\mathrm{ET}}{\mathrm{P}}\right)^{1-\mathrm{w}}
$$




$$
\begin{aligned}
& \left(\frac{\partial \mathrm{ET}}{\partial \mathrm{ET}_{0}}\right)_{\mathrm{P}, \Delta \mathrm{S}}=1-\left(1+\frac{1-(\mathrm{ET}+\Delta \mathrm{S}) / \mathrm{P}}{\phi+\Delta \mathrm{S} / \mathrm{P}}\right)^{1-\mathrm{w}}=\left(\frac{1+\phi-\mathrm{ET} / \mathrm{P}}{\phi+\Delta \mathrm{S} / \mathrm{P}}\right)^{1-\mathrm{w}} \\
& =(1+\phi-\mathrm{ET} / \mathrm{P})^{1-\mathrm{w}}(\phi+\Delta \mathrm{S} / \mathrm{P})^{\mathrm{w}-1}=\left(1+\frac{1-\mathrm{ET} / \mathrm{P}}{\phi}\right)^{1-\mathrm{w}}\left(1+\frac{\Delta \mathrm{S}}{\mathrm{ET}_{0}}\right)^{\mathrm{w}-1}
\end{aligned}
$$

A comparison of Equation (A5) with Equation (A2) shows that, indeed, $\mathrm{y}_{0}=-\Delta \mathrm{S} / \mathrm{ET}_{0}$.

The introduction of Equations (A4) and (A5) into the Euler relation, Equation (12), then produces the extended Fu model in the ML formulation [1]:

$$
\frac{\mathrm{ET}}{\mathrm{P}}=1+\phi-\left[1+\left(1+\frac{\Delta \mathrm{S}}{\mathrm{ET}_{0}}\right)^{\mathrm{w}} \phi^{\mathrm{w}}\right]^{1 / \mathrm{w}}(\Delta \mathrm{S}<0)
$$

which is in agreement with Equation (A3) and which, after rearrangement to solve for ET/P and factor $\mathrm{ET}_{0} / \mathrm{P}$ from the term $\frac{\mathrm{ET}_{0}+\Delta \mathrm{S}}{\mathrm{P}}$ inside the square brackets, is in agreement with Equation (31) as well. Thus, the model of Greve et al. [6] is a special case of the ML formulation, as was also concluded by Moussa and Lhomme [1]. However, Moussa and Lhomme [1] used the erroneous result for ET/P reported by Greve et al. [6] in making a comparison between the two models, leading them to present a spurious non-linear relationship between the parameter $\mathrm{y}_{0}$ and $-\Delta \mathrm{S} / \mathrm{ET}_{0}$.

\section{References}

1. Moussa, R.; Lhomme, J.-P. The Budyko functions under non-steady-state conditions. Hydrol. Earth Syst. Sci. 2016, 20, 4867-4879. [CrossRef]

2. Budyko, M.I. Climate and Life; Academic Press: New York, NY, USA, 1974.

3. Wang, C.; Wang, S.; Fu, B. Advances in hydrological modeling with the Budyko framework: A review. Prog. Phys. Geog. 2016, 40, 409-430. [CrossRef]

4. Sposito, G. Understanding the Budyko equation. Water 2017, 9. [CrossRef]

5. Du, C.; Sun, F.; Yu, J.; Liu, X.; Chen, Y. New interpretation of the role of water balance in an extended Budyko hypothesis in arid regions. Hydrol. Earth Syst. Sci. 2016, 20, 393-409. [CrossRef]

6. Greve, P.; Gudmundsson, L.; Orlowsky, B.; Seneveratne, S. A two-parameter Budyko function to represent conditions under which evapotranspiration exceeds precipitation. Hydrol. Earth Syst. Sci. 2016, 20, 2195-2205. [CrossRef]

7. Hankey, A.; Stanley, H.E. An alternate formulation of the static scaling hypothesis. Int. J. Quantum Chem. 1971, 5, 593-604. [CrossRef]

8. Andréassian, V.; Mander, Ü.; Oae, T. The Budyko hypothesis before Budyko: The hydrological legacy of Evald Oldekop. J. Hydrol. 2016, 535, 386-391. [CrossRef]

9. Sivapalan, M.; Yaeger, M.A.; Harmon, C.J.; Xu, X.; Troch, P.A. Functional model of water balance variability at the catchment scale: 1 . Evidence of hydrologic similarity and space-time symmetry. Water Resour. Res. 2011, 47, W02522. [CrossRef]

10. Jones, J.A.; Creed, I.F.; Hatcher, K.L.; Warren, R.J.; Adams, M.B.; Benson, M.H.; Boose, E.; Brown, W.A.; Campbell, J.L.; Covich, A.; et al. Ecosystem processes and human influences regulate streamflow response to climate change at long-term ecological research sites. Bioscience 2012, 62, 390-404. [CrossRef]

11. Arora, V.K. The use of the aridity index to assess climate change effect on annual runoff. J. Hydrol. 2002, 265, 164-177. [CrossRef]

12. Wang, D.; Tang, Y. A one-parameter Budyko model for water balance captures emergent behavior in Darwinian hydrologic models. Geophys. Res. Lett. 2014, 41, 4569-4577. [CrossRef]

13. Ye, S.; Li, H.-Y.; Li, S.; Leung, L.R.; Demissie, Y.; Ran, Q.; Blöschl, G. Vegetation regulation on streamflow intra-annual variability through adaptation to climate variations. Geophys. Res. Lett. 2015, 42, 10307-10315. [CrossRef]

14. Koster, R.D.; Suarez, M.J. A simple framework for examining the interannual variability of land surface moisture fluxes. J. Clim. 1999, 12, 1911-1917. [CrossRef]

15. Zhou, S.; Yu, B.; Huang, Y.; Wang, G. The complementary relationship and generation of the Budyko functions. Geophys. Res. Lett. 2015, 42. [CrossRef] 
16. Chen, X.; Alimohammadi, N.; Wang, D. Modeling inter-annual variability of seasonal evaporation and storage change based on the extended Budyko framework. Water Resour. Res. 2013, 49, 6067-6078. [CrossRef]

17. Istanbulluoglu, E.; Wang, T.; Wright, O.M.; Lenters, J.D. Interpretation of hydrologic trends from a water balance perspective: The role of groundwater storage in the Budyko hypothesis. Water Resour. Res. 2012, 48, W00H16. [CrossRef]

18. Yang, H.; Yang, D.; Lei, Z.; Sun, F. New analytical derivation of the mean annual water-energy balance equation. Water Resour. Res. 2008, 44, W03410. [CrossRef]

19. Zhang, L.; Hickel, K.; Dawes, W.R.; Chiew, F.H.S.; Western, A.W.; Briggs, P.R. A rational function approach for estimating mean annual evapotranspiration. Water Resour. Res. 2004, 40, W02502. [CrossRef]

20. Sankarasubramanian, A.; Vogel, R.M. Annual hydroclimatology of the United States. Water Resour. Res. 2002, 38, 19-1-19-12. [CrossRef]

21. Sankarasubramanian, A.; Vogel, R.M. Hydroclimatology of the United States. Geophys. Res. Lett. $2003,30$. [CrossRef]

22. Martínez, G.F.; Gupta, H.V. Toward improved identification of hydrological models: A diagnostic evaluation of the 'abcd' monthly water balance model for the conterminous United States. Water Resour. Res. 2010, 46, W08507. [CrossRef]

23. Li, D.; Pan, M.; Cong, Z.; Zhang, L.; Wood, E. Vegetation control on water and energy balance within the Budyko framework. Water Resour. Res. 2013, 49, 969-976. [CrossRef]

24. Xu, X.; Liu, W.; Scanlon, B. R.; Zhang, L.; Pan, M. Local and global factors controlling water-energy balances within the Budyko framework. Geophys. Res. Lett. 2013, 40, 6123-6129. [CrossRef]

25. Abatzoglou, J.T.; Ficklin, D.L. Climatic and physiographic controls of spatial variability in surface water balance over the contiguous United States using the Budyko relationship. Water Resour. Res. 2017, 53. [CrossRef]

26. Wang, X.-S.; Zhou, Y. Shift of annual water balance in the Budyko space for catchments with groundwater-dependent evapotranspiration. Hydrol. Earth Syst. Sci. 2016, 20, 3673-3690. [CrossRef]

(C) 2017 by the author. Licensee MDPI, Basel, Switzerland. This article is an open access article distributed under the terms and conditions of the Creative Commons Attribution (CC BY) license (http://creativecommons.org/licenses/by/4.0/). 